\title{
A NASALIDADE VOCÁLICA EM ESPANHOL: UM ESTUDO DE PERCEPÇÃO
}

\section{THE VOCALIC NASALITY IN SPANISH: A STUDY OF PERCEPTION}

\author{
Luciene Bassols Brisolara \\ Universidade Federal do Rio Grande \\ Rio Grande, Rio Grande do Sul, Brasil \\ Carmen Lúcia Barreto Matzenauer \\ Universidade Católica de Pelotas \\ Pelotas, Rio Grande do Sul, Brasil
}

RESUMO: Este estudo propõe-se investigar a percepção da vogal /a/ do espanhol, em contextos nasais, por uruguaios, considerando que a nasalização vocálica tem natureza alofônica nesta língua e que, segundo Akerberg (1999-2000) e Herrero de Haro (2011), não é percebida por falantes nativos de espanhol. O corpus para a realização da pesquisa foi constituído de uma amostra de nove falantes nativos de espanhol, com idade entre $18 \mathrm{e}$ 23 anos, moradores de Montevidéu e de Maldonado. Os participantes foram submetidos a quatro testes de percepção - três de discriminação e um de identificação , criados no software TP especificamente para o presente estudo. A análise do processo de percepção da vogal baixa tomou como base os estudos de Boomershine et al. (2008) e Herrero de Haro (2011), incluindo tratamento estatístico dos resultados. A análise dos dados indicou que, mesmo alofônica, a nasalidade vocálica é percebida em determinado índice e, embora nunca alcance percentual pleno, a percepção mostra-se mais facilitada em testes de discriminação do que no teste de identificação. Os resultados também apontam que a acuidade desse tipo de percepção parece independer da tonicidade da sílaba que hospeda a vogal.

PALAVRAS-CHAVE: Espanhol como Língua Materna; Percepção; Nasalização vocálica. Alofonia

ABSTRACT: This study intends to investigate the perception of the vowel /a/ of the Spanish, in nasal contexts, by uruguayans, considering that the vocalic nasalization has an allophonic nature in this language and that, according to Akerberg(1999-2000)and Herrero de Haro (2011), is not perceived by native speakers of 
Spanish. The corpus for the research was a sample of nine native Spanish speakers aged 18-23, residents of Montevideo and Maldonado. Participants were submitted to four perceptual tests - three of discrimination and one of identification - created in the TP software specifically for the present study. The analysis of the process of perception of the low vowel was based on the studies of Boomershineet al. (2008) and Herrero de Haro (2011), including statistical treatment of the results. The analysis of the data indicated that, even allophonic, vowel nasality is perceived in a certain index and, although never reaching full percentage, perception is more facilitated in discrimination tests than in the identification test. The results also point out that the accuracy of this type of perception seems to be independent of the stress of the syllable that hosts the vowel.

KEYWORDS: Spanish as First Language; Perception.Vowel Nasalization; Allophony 


\section{INTRODUÇÃO}

A nasalização vocálica é um fenômeno que, em espanhol, tem natureza alofônica e ocorre especialmente quando a vogal se encontra entre duas consoantes nasais ou quando está em início absoluto, seguida de consoante nasal (NAVARRO TOMÁS, 2004; QUILIS, 1999). Conforme Akerberg (1999-2000), as cinco vogais do sistema fonológico do espanhol podem apresentar-se sutilmente nasalizadas em contato com nasal, especialmente quando consoantes nasais as precedem e as seguem, sem cumprir função distintiva na língua.

Com interesse na percepção que falantes têm de fatos alofônicos de sua língua e tendo-se em conta que o grau de nasalidade atribuído a uma vogal baixa é maior e mais perceptível do que aquele que acompanha vogais não baixas, a presente investigação busca analisar se falantes nativos da variante uruguaia do espanhol percebem quando a vogal baixa é nasalizada ou se, conforme Akerberg (1999-2000) e Herrero de Haro (2011), não fazem distinção entre vogais orais e nasalizadas.

Com foco, portanto, na avaliação da percepção de um fato alofônico na gramática do espanhol por falantes nativos, considerando também a complexidade que pode implicar a percepção de unidades alofônicas em uma língua, o estudo visa responder às seguintes questões: a) o tipo e/ou o formato do teste de percepção influencia na maior acuidade da percepção da vogal /a/ oral e nasalizada? b) a tonicidade da vogal em estudo pode influenciar no maior ou menor índice de acertos nos testes de percepção?

Para responder a tais questões, foram elaborados quatro tipos de testes de percepção - três de discriminação e um de identificação -, todos criados no software TP (RAUBERet al., 2012). A análise estatística foi feita com o auxílio do software SPSS, versão 21.0.

\section{A PERCEPÇÃO DE SONS CONTRASTIVOS E NÃO CONTRASTIVOS}

A constituição do inventário fonológico de uma língua implica o funcionamento de contrastes, ou seja, diferenças de sons que estão relacionadas a diferenças de significado. Os contrastes são determinados por propriedades mínimas - os traços -, responsáveis pela construção da estrutura interna dos segmentos. Na gramática do espanhol, o inventário de vogais mostra contraste, por exemplo, identificado pela propriedade codificada pelo traço [ ${ }^{\prime}$ posterior], opondo, de um lado, as vogais /i, e/ (portadoras do traço [-posterior]) e, de outro, as vogais $/ \mathrm{u}, \mathrm{o} /$ (portadoras do traço [+posterior]). Essa é a motivação da diferença entre piso/peso e poso/puso. Diferentemente, o traço $[ \pm \mathrm{ATR}]^{1}$, por exemplo, é redundante no sistema vocálico do espanhol, porque não é responsável por determinar contraste entre vogais da língua: a realização da palavra café como

\footnotetext{
${ }^{1} \mathrm{O}$ traço $[ \pm \mathrm{ATR}]$ opõe vogais médias entre si: a média alta $[\mathrm{e}]$ à média baixa $[\varepsilon]$, e a média alta [o] à média baixa [o].
} 
caf $[e]$ ou caf $[\varepsilon]$ não altera o significado. Traços redundantes em um inventário fonológico diferenciam sons que, naquele sistema, têm o status de alofones. Neste mesmo plano está o traço [ \pm nasal] para a fonologia das vogais do espanhol, uma vez que é propriedade que não é capaz de criar contrastes, manifestando-se apenas com a característica de produzir formas alofônicas na língua.

Os segmentos que têm papel de alofones podem passar despercebidos, porque, não contrastando significado entre palavras, não cumprem papel decisivo na gramática. Já Trubetzkoy ([1939] 1971, p. 78), ao discutir a noção de oposição entre fonemas e a neutralização dessa oposição em determinados contextos, referia a diferença de percepção que falantes de uma língua têm quando dois segmentos se opõem na gramática: neste caso são "claramente distinguidos", e quando isso não ocorre, diz o autor, "frequentemente não é possível indicar qual dos dois foi produzido ou percebido".

Pelo desafio que a alofonia implica para questões relativas à percepção linguística, Boomershine et al. (2008) realizaram pesquisa com o objetivo de discutir o impacto de sons alofônicos e sons fonêmicos na percepção dos sons da fala. A investigação é aqui sumarizada, considerando-se o interesse para o foco do presente artigo, voltado para a percepção da nasalidade vocálica ${ }^{2}$ no espanhol, cujo status é alofônico.

$\mathrm{O}$ referido estudo contou com quatro experimentos aplicados a falantes de espanhol e de inglês. Os sons analisados foram os pares [d] - [r], [d] - [ð] e [r] $[ð]$, existentes em ambos os idiomas, mas com um comportamento fonológico diferente nas línguas investigadas: $[\mathrm{d}]-[\mathrm{r}]$ possuem contraste fonêmico no espanhol e alofônico no inglês, [d] - [ð] apresentam contraste fonêmico no inglês e alofônico no espanhol e [r] - [ð] têm contraste fonêmico em ambas as línguas.

No primeiro experimento, falantes nativos de espanhol e de inglês ${ }^{3}$, ouviram pares de sons com a sequência VCV [ada], [ara], [aða], [idi], [iri], [iði],[udu], [uru], [uðu], produzidos por locutores americanos, e os avaliaram como 'muito similares' ou 'muito diferentes'. No segundo, ouvindo os mesmos estímulos, indicaram se os pares eram 'iguais' ou 'diferentes'. $\mathrm{O}$ terceiro e o quarto experimentos foram idênticos aos anteriores, diferenciando-se dos dois primeiros porque os locutores eram gregos; essa escolha deveu-se ao fato de que, no grego, os fones [d], [r] e [ð] são contrastivos.

Os resultados dos quatro experimentos foram consistentes na indicação de que "falantes de uma língua em que um par de sons particular é contrastivo no

\footnotetext{
${ }^{2}$ Salienta-se que a nasalidade vocálica em contexto nasal é uma tendência universal, não sendo, portanto, exclusiva do espanhol. O fenômeno ocorre em diversas línguas, como o português (CAGLIARI, 1977; SEARA, 2000; SOUSA, 1994), o inglês (SOLÉ, 1992; STYLER, 2017) e o francês (ALCÂNTARA, 2016; STYLER, 2017; TRANEL, 1987). As línguas podem diferençar-se pelo status da nasalidade vocálica, já que pode ser contrastiva ou alofônica.

${ }^{3}$ Os participantes dos dois primeiros experimentos eram hispânicos, estudantes ou amigos de estudantes da The Ohio State University. Os falantes nativos de inglês eram estudantes de graduação da mesma universidade matriculados em cursos introdutórios de linguística.
} 
nível fonêmico percebem o par como sendo mais perceptualmente distintivo do que os falantes de uma língua em que o par não é fonemicamente contrastivo" (BOOMERSHINE et al., 2008, p. 163).Ficou evidenciado, portanto, que a capacidade de percepção se mostra diminuída quando falantes são expostos a sons que têm o status de alofones na sua língua.

Após a discussão sobre a percepção de sons que têm contraste fonêmico e de sons que são alofônicos, na seção 2.1, passa-se a apresentar uma breve descrição da nasalidade vocálica no espanhol.

\subsection{A nasalização vocálica em espanhol}

O espanhol apresenta um sistema vocálico de cinco fonemas orais: /i/, /e/, /a/, /o/ e /u/, que podem ser realizadas foneticamente como nasais, a depender do contexto em que estão inseridas. Quando produzidas de forma nasalizada, segundo Navarro Tomás (2004), não têm função distintiva na gramática da língua. A natureza fonética da nasalização vocálica no espanhol é atestada pelo autor quando diz que, em algumas ocasiões, a consoante nasal em final de sílaba influencia a vogal precedente, o que resulta em uma vogal nasalizada.

Segundo a Real Academia Española e a Asociación de Academias de La Lengua Española (2011), o contexto tem papel fundamental no processo de nasalização (o que confirma a natureza alofônica do processo no espanhol), pois a vogal sofre assimilação da propriedade nasal de uma consoante nasal contígua:

Pode afirmar-se, portanto, que o espanhol adota, com respeito à nasalização, as duas soluções menos marcadas e mais esperáveis fonologicamente: não possui segmentos contrastivos nasais em seu inventário de segmentos vocálicos, ainda que, por influência do contexto, possam aparecer realizações nasais que possuem caráter estritamente fonético (...). (REAL ACADEMIA ESPAÑOLA, ASOCIACIÓN DE ACADEMIAS DE LA LENGUA ESPAÑOLA, 2011, p. 104)

As vogais tendem a ser nasalizadas principalmente quando se encontram entre duas consoantes nasais (manar, mancha) e também quando a vogal é precedida por pausa e está em posição inicial de palavra, seguida de consoante nasal (hambre, ancestral), podendo apresentar diferentes manifestações fonéticas a depender da variedade do espanhol. Além disso, a nasalização é um processo que ocorre especialmente nos estilos de fala mais informais.

Para Vaquero de Ramírez (2003), no Caribe, a nasalização pode atingir todas as vogais de uma palavra que contenha uma consoante nasal (ex.:[sã liããõ]); esse processo é registrado pela autora além da nasalização que ocorre antes de consoante nasal em coda (ex.: pan $[$ pãn]), depois de consoante

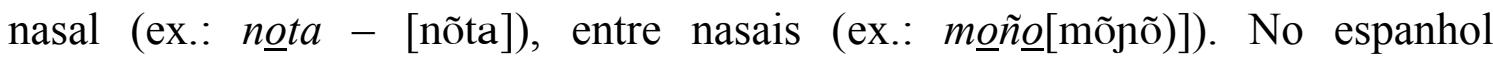
dominicano e em Porto Rico, ainda segundo Vaquero de Ramírez (2003), pode 
haver apagamento da nasal em coda, o que provocará uma forte nasalização na vogal precedente (ex.: tapón - [tapõ)]).

Considerando que o presente estudo discute a percepção da nasalização de vogais do espanhol em falantes nativos e atentando-se para o restrito número de pesquisas com esse foco, a Seção 2.2 traz uma síntese da pesquisa de Herrero de Haro (2011).

\subsection{A percepção da nasalização vocálica em espanhol - a análise de Herrero de Haro (2011)}

O estudo de Herrero de Haro (2011) analisou a percepção da nasalidade em vogais do espanhol por estudantes universitários falantes nativos da língua, com idade entre 21 e 23 anos, oriundos de Almería, Espanha, a fim de verificar se nativos de espanhol percebem ou não a nasalidade das vogais. Para tanto, o autor elaborou um teste de percepção contendo 15 perguntas, sendo 10 de classificação AX e 5 nas quais os indivíduos deveriam dizer se a sílaba ouvida era normal ou continha algum tipo de alteração.

Três testes foram propostos: no primeiro, os sujeitos escutaram vogais orais isoladas e as sequências de vogal mais consoante nasal, devendo avaliá-las como iguais ou diferentes; no segundo, os indivíduos ouviam vogais gravadas de forma isolada e vogais que foram separadas da consoante nasal, devendo avaliar se ambas eram percebidas como iguais ou diferentes; no terceiro teste, ouvindo as vogais orais unidas à consoante nasal, os sujeitos avaliavam se percebiam a sílaba como normal ou alterada.

Os resultados da pesquisa revelaram que, com relação ao primeiro teste, em $67 \%$ dos casos as vogais foram identificadas como iguais. No segundo teste, em $77 \%$ dos casos os sujeitos perceberam as vogais orais e as vogais nasais como sendo diferentes. Para Herrero de Haro (2011, p. 4), "ao separar as vogais da consoante nasal $n$, a nasalidade se torna óbvia, o que demonstra que os falantes de espanhol percebem diferenças nasais/orais, mas não são capazes de explicá-las". Quanto ao terceiro teste, em $80 \%$ dos casos, os indivíduos consideraram que havia ocorrido alguma alteração na sílaba ouvida, mas não sabiam explicar o fato.

Em suma, pode-se afirmar que os estudos de Boomershine et al. (2008) e de Herrero de Haro (2011) mostram a dificuldade de percepção de unidades alofônicas por falantes de uma língua, sendo que o segundo deles ainda evidencia que, mesmo quando a diferença entre alofones é percebida, os falantes não conseguem explicá-la ${ }^{4}$.

Discutida a questão da diferença de percepção entre propriedades que têm caráter fonêmico e aquelas que têm natureza alofônica em um sistema linguístico

\footnotetext{
${ }^{4}$ Considerando o limite de espaço para a apresentação dos resultados obtidos com este estudo e para a referência a outras pesquisas que trataram do mesmo tema, optou-se por não se trazerem fundamentos sobre percepção ou sobre processamento de fala.
} 
com a apresentação de dois estudos, descreve-se a metodologia utilizada na investigação aqui relatada sobre a percepção da nasalidade vocálica do espanhol.

\section{METODOLOGIA}

Os sujeitos ${ }^{5}$ do estudo foram nove falantes nativos de espanhol, uruguaios, seis mulheres e três homens, com idade entre 18 e 23 anos oriundos das cidades de Montevidéu $^{6}$ e Maldonado, estudantes da Facultad de Comunicación eInformación da Universidad de la República ${ }^{7}$.

Primeiramente, foram criados quatro testes de percepção da nasalidade vocálica em espanhol, com foco na vogal /a/: três testes de discriminação e um teste de identificação. Para a elaboração de cada teste, foram selecionadas palavras com a vogal /a/ precedida e/ou seguida de consoante nasal, todas dissilábicas ou trissilábicas; 24 palavras compuseram os Testes de Discriminação 1 e 2, e 22 compuseram o Teste de Discriminação 3 e o Teste de Identificação. Em metade das palavras havia contexto de nasalização vocálica no espanhol e, na outra metade, não. As palavras selecionadas são apresentadas na Seção 3.1. As palavras de cada teste foram aleatorizadas no site https://www.random.org/lists/.Na formatação dos testes, para a leitura das palavras pelos locutores, todas foram inseridas em frases-veículo e apresentadas em slides no Power Point, com um intervalo de 4 segundos entre uma frase e a outra.

Os estímulos foram gravados por dois locutores, um argentino, residente no Brasil, e uma brasileira, que viveu por mais de uma década na Argentina, tendo realizado seus estudos primários e secundários no país estrangeiro. Ambos os locutores, com idade próxima de 40 anos, são professores universitários de espanhol. ${ }^{8}$ A escolha de locutores de ambos os sexos deveu-se às implicações na percepção, pelos ouvintes, das diferenças entre a voz masculina e a voz feminina. Os estímulos foram gravados duas vezes por cada locutor e não foram normalizados.

\footnotetext{
${ }^{5}$ Esta pesquisa tem a aprovação do Comitê de Ética - Processo $\mathrm{n}^{\mathrm{o}}$ 68282417.3.0000.5339e todos os participantes assinaram um Termo de Consentimento Livre e Esclarecido.

${ }^{6}$ Inicialmente participariam do estudo apenas indivíduos de Montevidéu, no entanto, devido à dificuldade de encontrar universitários que não falassem português, optou-se por incluirestudantes que residiam em Maldonado, que fica a aproximadamente $120 \mathrm{~km}$ de Montevidéu.

${ }^{7}$ Expressa-se aqui especial agradecimento às professoras Beatriz Gabbiani, Virginia Bertolotti e Yamila Montenegroda Universidad de la República, peloapoio na operacionalização da coleta de dados.

${ }^{8}$ Sobre a escolha dos locutores que gravaram os estímulos para o estudo, salienta-se que, pela alta proficiência que têm nas duas línguas, pode concluir-se ser sua produção muito semelhante à de um falante de espanhol monolíngue. Mesmo assim, na continuidade da pesquisa será feita a gravação dos estímulos exclusivamente com monolíngues falantes de espanhol.
} 
As gravações dos testes pelos locutores foram feitas em uma cabine acústica, com um microfone com taxa de amostragem de $44.100 \mathrm{~Hz}, 16$ bits. Gravadas as frases-veículo, delas foram segmentadas as palavras com o uso do Programa Praat (BOERSMA; WEENINK, 2008), e salvas em arquivos individuais no formato .wav. Tais palavras compuseram os estímulos para os testes de percepção, os quais foram elaborados no Software TP (RAUBERet al. 2012). No TP, os estímulos foram aleatorizados automaticamente, alternando os locutores, escolhendo metade das produções da voz masculina e metade da voz feminina.

Para a avaliação da percepção pelos sujeitos da pesquisa, foram aplicados os três testes de discriminação e um de identificação, com o uso do software TP. A aplicação deu-se em outubro de 2017, em uma sala da UDELAR, com o uso de um computador portátil e de fones de ouvido.

\subsection{Descrição dos testes de percepção}

No Teste de Discriminação 1, formato AX - identidade de palavra, os sujeitos da pesquisa deveriam ouvir dois estímulos em espanhol e dizer se eram iguais ou diferentes. As palavras, que eram ouvidas duas vezes, continham a vogal /a/ nasalizada e/ou não nasalizada. As duplas de palavras poderiam: (a) ser iguais, contendo a vogal /a/ nasalizada; (b) ser iguais, contendo a vogal /a/ não nasalizada; ou (c) ser diferentes, contendo uma ocorrência da vogal /a/ nasalizada e outra não nasalizada.

No Teste de Discriminação 2, formato $A B X$ - identidade de palavra, os estudantes deveriam ouvir três estímulos em espanhol e responder se o terceiro estímulo era igual ao primeiro (ex.: gu[a]nte - gu[ã]nte - gu[a]nte) ou ao segundo (ex.: gu[ã]nte - gu[a]nte - gu[a]nte).

No Teste de Discriminação 3 , formato $A X$ - identidade de língua, os alunos deveriam ouvir duas palavras diferentes e responder a quatro possibilidades: (a) a primeira palavra está em espanhol e a segunda, em português (ex.: antojo - lambada); (b) a primeira palavra está em português e a segunda, em espanhol (ex.: pitanga - andoba); (c) as duas estão em espanhol (ex.: legaña chamba), ou, ainda, (d) as duas estão em português (ex.: pitanga - frango).

Particularmente o Teste de Discriminação 3, reunindo palavras em espanhol e em português, teve o objetivo de verificar o reconhecimento ou não, por falantes nativos de espanhol, do funcionamento que a nasalização (ou não nasalização) vocálica apresenta na sua língua. A proposição desse teste decorreu do entendimento de que um caminho para testar-se o conhecimento internalizado que falantes têm da gramática da sua língua é confrontá-la com a de outra língua, mesmo que esta não seja por eles dominada. Nesse sentido, o Teste de Discriminação 3 serviu para subsidiar o conhecimento fonológico do falante nativo de espanhol.

No Teste de Identificação, os participantes deveriam ouvir uma palavra em espanhol e dizer se a vogal /a/ diante de nasal era produzida como oral (ex.: $\mathrm{p}[\mathrm{a}]$ nfleto) ou nasal (ex.: $\mathrm{m}[\tilde{a}]$ ndato). 
Os Quadros 1, 2, 3 e 4 apresentam as palavras que integraram os testes de percepção.

Quadro 1: Palavras que integraram o Teste de Discriminação 1

\begin{tabular}{cccc}
\hline \multicolumn{2}{c}{ Vogal Tônica } & \multicolumn{2}{c}{ Vogal Átona } \\
\hline Nasal & Oral & Nasal & Oral \\
\hline mano & campo & andar & cantor \\
mancha & banco & mandón & tambor \\
ángel & dama & ambiguo & gangrena \\
hampa & mengano & manguito & candileja \\
ancho & huraño & hambruna & pandit \\
nance & chándal & amantillo & cambute \\
\hline
\end{tabular}

Fonte: As autoras

Quadro 2: Palavras que integraram o Teste de Discriminação 2

\begin{tabular}{cccc}
\hline \multicolumn{2}{c}{ Vogal Tônica } & \multicolumn{2}{c}{ Vogal Átona } \\
\hline Nasal & Oral & Nasal & Oral \\
\hline semana & amo & ambición & bambú \\
manco & daño & anchoa & fantasma \\
manga & santo & amansar & fantoche \\
mandria & fámulo & andóbal & gandir \\
mangla & guante & angazo & ganforro \\
atamán & calambre & mantel & lancurdia \\
\hline
\end{tabular}

Fonte: As autoras

Quadro 3: Palavras que integraram o Teste de Discriminação 3

\begin{tabular}{cccc|cccc}
\hline \multicolumn{4}{c|}{ Espanhol } & \multicolumn{4}{c}{ Português } \\
\hline \multicolumn{2}{c|}{ Vogal Tônica } & \multicolumn{2}{c|}{ Vogal Átona } & \multicolumn{3}{c}{ Vogal Tônica } & Vogal Átona \\
\hline Nasal & Oral & Nasal & Oral & \multicolumn{4}{c}{ Nasal } \\
\hline hambre & chamba & ambón & francolín & mangra & frango & manchete & lambada \\
hanzo & zanja & andoba & panceta & manja & morango & mancal & bandagem \\
caimán & legaña & antojo & & & pitanga & mandraca & bangalô \\
\hline
\end{tabular}

Fonte: As autoras 
Quadro 4: Palavras que integraram o Teste de Identificação

\begin{tabular}{cccc}
\hline \multicolumn{2}{c}{ Vogal Tônica } & \multicolumn{2}{c}{ Vogal Átona } \\
\hline Nasal & Oral & Nasal & Oral \\
\hline manto & lámpara & manera & bandido \\
manso & urbano & antigua & panfleto \\
máncer & pánico & mandato & zanfona \\
manfla & danto & mangrullo & bandujo \\
almante & fango & ampuloso & candado \\
& alacrán & & gambocho \\
\hline
\end{tabular}

Fonte: As autoras

Definidos os sujeitos da pesquisa e descritos os testes de percepção, passase à apresentação e à discussão dos resultados.

\section{RESULTADOS}

Nesta seção, apresentam-se a descrição e a análise dos resultados obtidos por meio dos quatro testes de percepção aplicados neste estudo. Submeteram-se os dados a tratamento estatístico através do Software SPSS, versão 21.0, para a descrição acurada dos resultados e a testagem das hipóteses. Preliminarmente, verificou-se se os dados atendiam ao pressuposto da normalidade, aplicando os testes Kolmogorov-Smirnov e Shapiro-Wilks. Em sendo a distribuição normal ${ }^{9}$, foi aplicado o teste $\mathrm{T}$ para amostras emparelhadas; caso contrário, foi aplicado o teste Wilcoxon.

\subsection{Teste de discriminação 1}

Os resultados gerais do Teste de Discriminação 1 (formato $A X$-identidade de palavra) indicaram um percentual médio de acertos de 93\%. Na Tabela 1, mostram-se os resultados relativos à média de acertos de vogais iguais e diferentes.

${ }^{9}$ A distribuição foi considerada normal quando, ao aplicar os testes KolmogorovSmirnov e Shapiro-Wilks, ao menos um deles apresentasse $\mathrm{p}>0,05$. Caso contrário, a distribuição foi considerada não normal. 
Tabela 1: Média de discriminação correta de vogais iguais e diferentes, desvio padrão, mínimo e máximo

\begin{tabular}{ccccc}
\hline & Média & Desvio padrão & Mínimo & Máximo \\
\hline Acertos - vogais iguais & 98,67 & 4,00 & 88 & 100 \\
Acertos - vogais diferentes & 87,67 & 10,64 & 67 & 100 \\
\hline
\end{tabular}

Fonte: As autoras

Conforme os dados da Tabela 1, os uruguaios percebem com maior acuidade a vogal /a/ quando ambos os estímulos são iguais, o que é confirmado pelo teste não paramétrico Wilcoxon $(Z=-2,254$, p. 0,024$)$. Diferentemente do estudo de Herrero de Haro (2011), os sujeitos da presente pesquisa apresentam um percentual médio alto de acertos de vogais diferentes. A não convergência dos resultados desta investigação e daquela realizada por Herrero de Haro pode ser decorrente das diferenças metodológicas dos dois estudos, como também da variedade do espanhol, já que, naquela pesquisa, os sujeitos são da Espanha e, nesta, são do Uruguai, sendo que o grau de nasalização fonética pode mostrar diversidade em uma e outra variedade da língua.

$\mathrm{Na}$ Tabela 2, trazem-se os resultados referentes à média de acertos de vogais em sílabas tônicas e átonas.

Tabela 2: Média de discriminação correta de vogais em sílabas tônicas e átonas, desvio padrão, mínimo e máximo

\begin{tabular}{ccccc}
\hline & Média & Desvio padrão & Mínimo & Máximo \\
\hline Acertos - síl. tônicas & 89,00 & 10,40 & 67 & 100 \\
Acertos - síl. átonas & 97,33 & 4,00 & 88 & 100 \\
\hline
\end{tabular}

Fonte: As autoras

O resultado apresentado na Tabela 2 evidencia que os falantes nativos de espanhol percebem com maior acuidade a vogal /a/ quando se encontra em posição átona, o que é evidenciado no resultado do teste Wilcoxon $(Z=-1,973$, p. 0,049 ). Ainda que haja diferença estatística significativa entre vogais tônicas e átonas e que as átonas apresentem quase $100 \%$ de acuidade, é possível verificar que, na posição tônica, o índice de acertos também é bastante representativo.

Conforme registram os resultados nas Tabelas 1 e 2, o Teste de Discriminação 1 revelou que os sujeitos da pesquisa discriminam em maior índice a vogal /a/ quando ambos os estímulos são iguais e quando a vogal em estudo pertence à sílaba átona.

\subsection{Teste de discriminação 2}

No Teste de Discriminação 2 (formato $A B X$ - identidade de palavra), o percentual médio de acertos foi de $89,33 \%$. Na Tabela 3, estão os resultados relativos à média de acertos do primeiro estímulo e do segundo estímulo 
separadamente, a fim de observar-se se há diferenças no percentual de acuidade na percepção dos estudantes.

Tabela 3: Média de discriminação correta do primeiro estímulo e do segundo, desvio padrão, mínimo e máximo

\begin{tabular}{cllll}
\hline & Média & Desvio padrão & Mínimo & Máximo \\
\hline $\begin{array}{c}\text { Acertos - primeiro } \\
\text { estímulo }\end{array}$ & 86,11 & 10,27 & 71 & 100 \\
$\begin{array}{c}\text { Acertos - segundo } \\
\text { estímulo }\end{array}$ & 92,78 & 5,04 & 83 & 100 \\
\hline
\end{tabular}

Fonte: As autoras

A Tabela 3 indica que, embora haja um alto percentual médio para os dois estímulos, os sujeitos da pesquisa mostram sucesso pouco maior no caso do segundo estímulo, conforme aponta o resultado do Teste $\mathrm{T}$ para amostras emparelhadas $(\mathrm{t}(8)=-1,911, \mathrm{p} .0,092)$. No entanto, considerando o valor de $\mathrm{p}$ que é maior do que 0,05 e menor do que 0,10 , é preciso salientar que essa diferença é marginalmente significativa (MARTINS, 2011). Ressalta-se que o desvio padrão é maior para o primeiro estímulo do que para o segundo, o que indica que há menor dispersão em torno da média para o segundo estímulo.

$\mathrm{Na}$ Tabela 4, trazem-se os resultados referentes à média de acertos de vogais em sílabas tônicas e átonas.

Tabela 4: Média de discriminação correta de vogais em sílabas tônicas e átonas, desvio padrão, mínimo e máximo

\begin{tabular}{lllll}
\hline & Média & Desvio padrão & Mínimo & Máximo \\
\hline Acertos - síl. tônicas & 89,44 & 7,41 & 79 & 96 \\
Acertos - síl. átonas & 88,56 & 7,87 & 75 & 96 \\
\hline
\end{tabular}

Fonte: As autoras

Considerando os resultados da Tabela 4, vê-se que não há diferenças significativas no percentual de acertos da vogal /a/ no que tange à tonicidade da sílaba que hospeda a vogal em estudo, conforme é revelado pelo Teste $\mathrm{T}$ para amostras emparelhadas $(\mathrm{t}(8)=0,273$, p. 0,792), diferentemente do que ocorreu no Teste de Discriminação 1, embora deva ressaltar-se que naquele teste a diferença é pouco expressiva.

Como se pode observar, o Teste de Discriminação 2 mostrou que há um alto índice geral de acerto e, considerando os resultados mostrados na Tabela 4, é possível verificar que, apesar de a média de acertos ter sido um pouco maior no segundo estímulo, não é muito distante da média do primeiro estímulo, o que é confirmado pelo teste $\mathrm{T}$ para amostras emparelhadas, que revela uma diferença marginalmente significativa. Neste Teste de Discriminação, a tonicidade não se 
revelou fator relevante para a maior acuidade da percepção da nasalidade vocálica.

\subsection{Teste de discriminação 3}

Os resultados gerais do Teste de Discriminação 3 (formato $A X$ - identidade de língua) forneceram um percentual médio de acertos de $72 \%$.A Tabela 5 contém os resultados relativos à média de acertos do teste para cada uma das quatro alternativas (veja-se Seção 3.1).

Tabela 5: Média de discriminação correta de palavras espanhol e/ou português, desvio padrão, mínimo e máximo

\begin{tabular}{cllll}
\hline & Média & Desvio padrão & Mínimo & Máximo \\
Português-Espanhol & 78,89 & 25,22 & 40 & 100 \\
Espanhol-Português & 63,00 & 11,15 & 50 & 100 \\
Português-Português & 87,00 & 17,74 & 50 & 100 \\
Espanhol-Espanhol & 56,67 & 25,49 & 20 & 90 \\
\hline
\end{tabular}

Fonte: As autoras

Ao ser comparado o percentual médio de acertos para Português-Espanhol (PE) e Espanhol-Português (EP), os dados expressam que os uruguaios apresentam maior índice de acertos quando o primeiro estímulo pertence ao português e o segundo ao espanhol, conforme evidencia o resultado do teste paramétrico $\mathrm{T}$ para amostras emparelhadas $(\mathrm{t}(8)=2,705, \mathrm{p}$. 0,027). Considerando as alternativas Português-Português (PP) e Espanhol-Espanhol (EE), há um maior percentual médio de acertos na opção PP, o que é também revelado como significativo pelo teste não paramétrico Wilcoxon( $Z=-2,431$, p. 0,015$)$.

$\mathrm{Na}$ Tabela 5, é possível perceber que o falante nativo de espanhol apresenta menor acuidade em se tratando da percepção da nasalidade em sua língua materna, como pode ser observado nas alternativas $\mathrm{PE} / \mathrm{EP}$, em que os sujeitos da pesquisa acertam mais na discriminação do par PE, e nas alternativas $\mathrm{PP} / \mathrm{EE}$, em que há maior índice de acertos em PP.

Considerando que o Teste de Discriminação 3 visava à avaliação do conhecimento que o falante evidencia da gramática da sua língua, os resultados revelados na Tabela 5 devem ser interpretados com este viés: o falante rejeita formas que não integram o funcionamento da sua língua materna e as classifica como pertencentes a outro sistema linguístico. O maior número de acertos das alternativas Português-Português do que daquelas Espanhol-Espanhol pode ser atribuído a esse fato, especialmente pela presença da recorrência da nasalização vocálica nos dois itens lexicais ouvidos em sequência. 


\subsection{Teste de identificação}

O Teste de Identificação mostrou um percentual geral de acertos de 48,67\%, o índice mais baixo evidenciado considerando-se os quatro testes de percepção. A Tabela 6 registra a média de acertos da percepção da vogal baixa oral e nasal.

Tabela 6: Média de identificação correta de vogal/a/ oral ou nasal, desvio padrão, mínimo e máximo

\begin{tabular}{lllll}
\hline & Média & Desvio padrão & Mínimo & Máximo \\
\hline Acertos - vogal oral & 65,78 & 15,78 & 41 & 86 \\
Acertos - vogal nasal & 30,33 & 12,16 & 5 & 50 \\
\hline
\end{tabular}

Fonte: As autoras

Na Tabela 6, os dados evidenciam que os uruguaios identificam com maior acuidade a vogal /a/ produzida como oral em comparação com a sua contraparte nasal. $\mathrm{O}$ Teste $\mathrm{T}$ para amostras emparelhadas relevou que essa diferença é significativa $(\mathrm{t}(8)=4,379$, p. 0,002$)$. Esse resultado pode ser corroborado pelos estudos de Akerberg (1999-2000) e Herrero de Haro (2011), que afirmam que os falantes nativos de espanhol não têm consciência da nasalidade na sua LM. O baixo índice de acuidade na percepção da vogal nasal pode ser resultado da alofonia da nasalidade vocálica no espanhol, o que é corroborado pelo estudo de Boomershine et al. (2008), que evidenciou que falantes de espanhol e de inglês percebem com maior facilidade sons diferentes quando são contrastivos fonologicamente e têm dificuldade de diferenciar sons alofônicos, considerandoos iguais.

A Tabela 7 mostra a média de acertos da vogal baixa em sílaba tônica e átona.

Tabela 7: Média de identificação correta de vogais em sílabas tônicas e átonas, desvio padrão, mínimo e máximo

\begin{tabular}{lllll}
\hline & Média & Desvio padrão & Mínimo & Máximo \\
\hline Acertos - síl. tônicas & 55,78 & 6,96 & 45 & 64 \\
Acertos - síl. átonas & 50,56 & 11,57 & 32 & 68 \\
\hline
\end{tabular}

Fonte: As autoras

$\mathrm{Na}$ Tabela 7, os dados revelam que não há diferença significativa entre o percentual de acuidade no que tange à tonicidade da sílaba que hospeda a vogal $/ \mathrm{a} /(\mathrm{t}(8)=1,161, \mathrm{p} .0,279)$.

A observação conjunta dos resultados apresentados nas Tabelas 6 e 7 leva ao entendimento de que nativos de espanhol apresentam maior acuidade na identificação da vogal /a/ produzida como oral e que a tonicidade não se mostra 
relevante para a maior ou menor capacidade da percepção que têm da presença ou não da nasalidade na vogal.

\section{CONCLUSÕES}

Retomando-se as duas questões de pesquisa propostas, a primeira obteve resposta positiva e a segunda, negativa: o tipo e/ou o formato do teste de percepção parece poder, sim, influenciar na maior acuidade da percepção da vogal /a/oral e nasalizada, já que a percepção se mostra mais facilitada em testes de discriminação do que no teste de identificação; por outro lado, a acuidade desse tipo de percepção parece independer da tonicidade da sílaba que hospeda a vogal.

Os resultados dos Testes de Discriminação revelaram um elevado percentual médio de acertos nos três testes aplicados (Teste de Discriminação $1=$ 93\%; Teste de Discriminação 2= 89,33\% e Teste de Discriminação 3=72\%), diferentemente do que foi evidenciado no Teste de Identificação (48,67\%). Esse resultado pode levar à interpretação de que o tipo de teste pode influenciar nos resultados da pesquisa ${ }^{10}$, o que é corroborado pelo estudo de Brisolara \& Matzenauer $(2018)^{11}$. Os altos índices percentuais registrados, especialmente nos Testes de Discriminação 1 e 2, podem ser resultantes do menor custo de processamento exigido por tais testes, já que o indivíduo ouve dois ou três estímulos e escolhe uma das alternativas, recorrendo à memória de curto prazo. No que tange ao Teste de Identificação, o indivíduo ouve um estímulo e tem de recorrer ao conhecimento fonético-fonológico que tem armazenado de sua língua materna, a fim de responder se a vogal é oral ou nasal.

O menor percentual médio no Teste de Discriminação 3, comparado aos outros Testes de Discriminação, pode ser atribuído ao formato do teste, que é bastante semelhante ao Teste de Identificação, no sentido de que o indivíduo ouve dois estímulos e tem de recorrer ao conhecimento fonético-fonológico que possui de sua LM, a fim de responder se os estímulos pertencem à gramática do espanhol ou não. O objetivo deste teste, conforme já explicitado, foi o de verificar se falantes nativos de espanhol, ao ouvir um estímulo com uma forte nasalização, seriam capazes de rejeitá-lo, considerando-o não pertencente a seu idioma. Portanto, o fato de, neste Teste de Discriminação, a maior acuidade dar-se quando ambos os estímulos estão em português indica que os sujeitos da pesquisa conseguem identificar sons nasalizados, como os que ocorrem no português.

Verificando-se os resultados obtidos nos testes deste estudo, é possível dizer-se que, mesmo sendo alofônica, a nasalidade vocálica é percebida em determinado índice por falantes de espanhol do Uruguai, embora a percepção nunca alcance percentual pleno. Considerando-se o baixo índice de acertos no Teste de Identificação, é possível concluir-se que os falantes nativos de espanhol

\footnotetext{
${ }^{10}$ Ver Gerrits (2001) e Gerrits \& Schouten (2004).

${ }^{11} \mathrm{O}$ estudo de Brisolara \& Matzenauer (2018) encontra-se no prelo.
} 
são capazes, em algum nível, de perceber a nasalização vocálica na sua língua, embora possam não ter consciência clara do que está ocorrendo, o que pode ser atribuído ao fato de o fenômeno tem caráter alofônico, o que vai ao encontro do estudo de Boomershine (2008).

A análise estatística dos resultados evidenciou que os sujeitos da pesquisa discriminam a vogal /a/ com maior acuidade quando os estímulos são iguais, apresentando quase $100 \%$ de acertos, e que a tonicidade só mostrou ser relevante no Teste de Discriminação 1, indicando que os indivíduos percebem com maior acurácia quando a vogal está em posição átona; no entanto, o resultado relativo à tonicidade da vogal em estudo precisa ser relativizado, tendo em vista que, no Teste de Discriminação 2 e no Teste de Identificação, este fator não evidenciou relevância. Com relação ao Teste de Discriminação 3, foi possível observar que há maior índice de acertos nos pares PE e PP, em comparação com os pares EP e EE. Esse resultado, reunido àquele observado no Teste de Identificação, em que houve um alto índice de acertos quando a vogal é oral em comparação com a vogal nasal, reforça a interpretação de que os nativos de espanhol têm dificuldade de perceber a nasalização vocálica em sua língua materna.

O presente estudo evidencia, portanto, que fatos alofônicos podem ser percebidos pelos falantes de uma língua, mas essa percepção ocorre em baixo grau, especialmente ao tratar-se de processamento de identificação. Nesse sentido, tem-se a confirmação de que o uso de um sistema linguístico exige do falante precipuamente a percepção e a produção das unidades que são contrastivas na gramática.

\section{REFERÊNCIAS}

ALCÂNTARA, C. C. "A nasalidade contrastiva do francês por falantes nativos do português brasileiro". In: ALVES, U. K. Aquisição fonético-fonológica de língua estrangeira: investigações rio-grandenses e argentinas em discussão. Campinas: Pontes Editores, 2016, p. 49-63.

AKERBERG, Marianne. Las vocales nasales en portugués: un problema de percepción. Estudios de Lingüistica Aplicada.v.17, n. 30/31, p. 37-52, 1999-2000.

BOERSMA, P; WEENINK, D. Praat. Doing Phonetics by Computer (versão 5.3.84).2014. Disponível em: $<$ http://www.fon.hum.uva.nl/praat/>.

BOOMERSHINE, A. et al. The impact of allophony versus contrast on speech perception. In: AVERY, Pet al. (ed.) Contrast in phonology: theory, perception, acquisition. Berlin: Mounton de Gruyter, 2008.

BRISOLARA, L. B; MATZENAUER, C. L. B. A percepção da vogal /a/ do espanhol, em contextos nasais, por brasileiros. Revista Gradus. No prelo. 2018. 
CAGLIARI, Luiz Carlos. An experimental study of nasality with particular reference to Brazilian Portuguese, Tese de Doutorado, University of Edinburgh, Edinburgo, 1977.

GERRITS, E. The categorization of speech sounds by adults and children: a study of the categorical perception hypothesis and the developmental weighting of acoustic speech cues. Tese (Doutorado) - Utrecht University, The Netherlands, LOT series, 2001.

GERRITS, E; SCHOUTEN, M. E. H. Categorical perception depends on the discrimination task. Perception \& Psychophysics. 2004, 66 (3), 363-376.

HERRERO DE HARO, A. La percepción de la nasalidad en las vocales españolas. Vida Hispánica, vol. 44, 2011, pp. 12-15.

MARTINS, C. Manual de análise de dados quantitativos com recurso ao IBM SPSS: saber decidir, fazer, interpretar e redigir. BRAGA: Psiquilibrios Edições, 2011.

NAVARRO TOMÁS, T. Manual de pronunciación española. Madrid: CSIC, 2004.

QUILIS, A. Tratado de fonología y fonética españolas.Madrid: Editorial Gredos, 1999.

RAUBER, A. Set al. TP: perception tests and perceptual training with immediate feedback, versão 2.0. Acesso em 15 out. 2012. Disponível em:

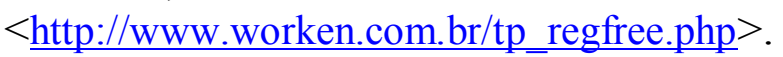

REAL ACADEMIA ESPAÑOLA; ASOCIACIÓN DE ACADEMIAS DE LA LENGUA ESPAÑOLA. Nueva gramática de la lengua española: fonética y fonología. Barcelona: Espasa, 2011.

SEARA, I. C. Estudo acústico-perceptual da nasalidade das vogais do Português Brasileiro, Tese de Doutorado, Universidade Federal de Santa Catarina, Florianópolis, 2000.

SOLÉ, M. J. Phonetic and phonological processes: The case of nasalization. Language and Speech, 35 (1-2), 29-43.

SOUSA, E. M. G. Para a caracterização fonético-acústica da nasalidade no português do Brasil, Dissertação de Mestrado, Universidade Estadual de Campinas, Campinas, 1994.

STYLER, W. On the acoustical features of vowel nasality in English and French. J. Acoust. Soc. Am. 142 (4), October 2017. 
TRANEL, B. The sounds of French: an introduction. Cambridge: Cambridge University Press, 1987.

TRUBETZKOY, N. Principles of Phonology. Tradução para o inglês de Christiane Baltaxe. $2^{\mathrm{a}}$ reimpressão. Berkeley and Los Angeles: University of California Press, [1939] 1971.

VAQUERO DE RAMÍREZ, M. El español de América I: pronunciación. Cuaderno de Lengua Española 28. Madrid: Arco/Libros, S.L., 2003.

Luciene Bassols Brisolara LucieneBrisolara@furg.br

Carmen Lúcia Barreto Matzenauer Carmen.Matzenauer@gmail.com

Recebido em: 16 fev. 2018 Aceito em: 15 jun. 2018 Publicado em: 19 ago. 2018 